\title{
The potential use of pumice in mine backfill
}

\author{
Mohammed A. Hefni (D) \\ Mining Engineering Department, King Abdulaziz University, Jeddah, Saudi Arabia \\ Corresponding author. E-mail: mhefni@kau.edu.sa
}

(Received 17 October 2020; Revised 14 November 2020; Accepted 15 November 2020)

\begin{abstract}
The use of natural pozzolans in concrete applications is gaining more attention because of the associated environmental, economic, and technical benefits. In this study, reference cemented mine backfill samples were prepared using Portland cement, and experimental samples were prepared by partially replacing Portland cement with 10 or $20 \mathrm{wt} . \%$ fly ash as a byproduct (artificial) pozzolan or pumice as a natural pozzolan. Samples were cured for 7, 14, and 28 days to investigate uniaxial compressive strength development. Backfill samples containing $10 \mathrm{wt} . \%$ pumice had almost a similar compressive strength as reference samples. There is strong potential for pumice to be used in cemented backfill to minimize costs, improve backfill properties, and promote the sustainability of the mining industry.
\end{abstract}

Keywords: Backfill; Cement; Pozzolans; Pumice; Uniaxial compressive strength

\section{Objective}

The goal of this project is to investigate if partially replacing Portland cement with fly ash or pumice affects the uniaxial compressive strength (UCS) of mine backfill.

\section{Introduction}

Pozzolans are siliceous or siliceous and aluminous materials that react with the calcium hydroxide $(\mathrm{CaOH})$ released during cement hydration to produce compounds with cementing properties. Pozzolans are widely used in civil and mining applications to reduce costs and improve the mechanical and physical properties of concrete. Cement can account for up to $75 \%$ of mine backfill costs; therefore, it is common practice in the mining industry to partially replace relatively expensive cement with relatively inexpensive pozzolans (Edraki et al., 2014). Examples of artificial pozzolans are slag and fly ash, and examples of natural pozzolans are volcanic ash and the pumice formed during lava solidification. Artificial pozzolans are widely used, but natural pozzolans have not been fully exploited, although they are abundant in many countries. For example, Saudi Arabia is fortunate to have a large resource of natural pozzolans, and research is ongoing to investigate their use in the concrete industry (Al-Amoudi et al., 2019; Celik et al., 2014; Kupwade-Patil et al., 2016; Moufti et al., 2000). In this study, pumice was investigated for its potential use in mine backfill compared with fly ash and cement.

\section{Methods}

Backfill samples were prepared using tailings from a nickel mine in Canada. Figure 1 shows the particle size distribution and Table 1 summarizes the physical properties of the tailings. Control samples were

\footnotetext{
(C) The Author(s), 2020. Published by Cambridge University Press. This is an Open Access article, distributed under the terms of the Creative Commons Attribution licence (http://creativecommons.org/licenses/by/4.0/), which permits unrestricted re-use, distribution and reproduction, provided the original article is properly cited.
} 


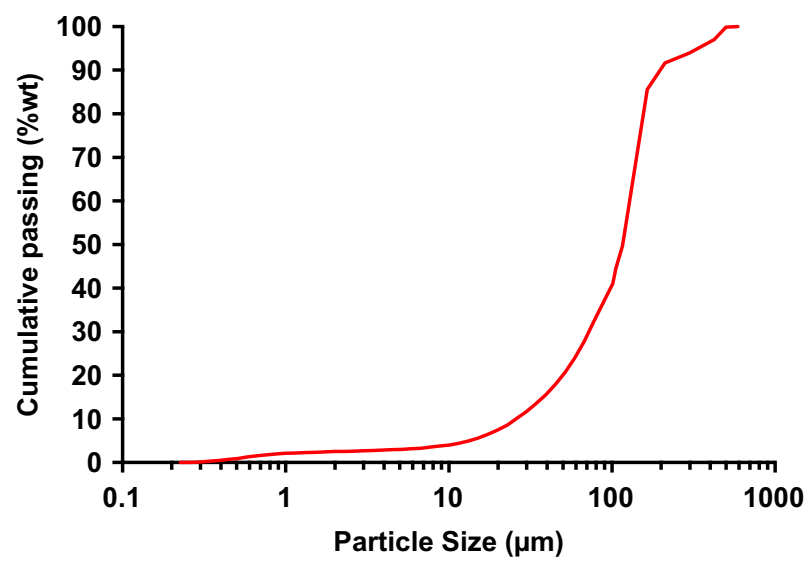

Figure 1. Particle size distribution of tailings from a nickel mine in Canada

Table 1. Physical properties of tailings from a nickel mine in Canada

\begin{tabular}{cccccccc}
\hline $\begin{array}{l}\text { D10 } \\
\mu \mathrm{m}\end{array}$ & $\begin{array}{l}\mathrm{D} 30 \\
\mu \mathrm{m}\end{array}$ & $\begin{array}{c}\mathrm{D} 50 \\
\mu \mathrm{m}\end{array}$ & $\begin{array}{c}\mathrm{D} 60 \\
\mu \mathrm{m}\end{array}$ & $\begin{array}{l}\mathrm{D} 90 \\
\mu \mathrm{m}\end{array}$ & $\begin{array}{c}\text { Coefficient of } \\
\text { uniformity }\end{array}$ & $\begin{array}{c}\text { Coefficient of } \\
\text { curvature }\end{array}$ & $\begin{array}{c}\text { Specific } \\
\text { gravity }\end{array}$ \\
\hline 4.15 & 73.62 & 115.3 & 127.3 & 199.6 & 30.7 & 10.3 & 2.7 \\
\hline
\end{tabular}

Table 2. Five backfill treatments tested

\begin{tabular}{lccc}
\hline Mixture ID & Portland cement (wt.\%) & Fly ash (wt.\%) & Pumice (wt.\%) \\
\hline PC & 100 & 0 & 0 \\
\hline FA10 & 90 & 10 & 0 \\
\hline FA20 & 80 & 20 & 0 \\
\hline PUM10 & 90 & 0 & 10 \\
\hline PUM20 & 80 & 0 & 20 \\
\hline
\end{tabular}

prepared with general use Portland cement. Experimental samples were prepared with class $\mathrm{F}$ fly ash or pumice, which comprises mainly silicon dioxide (amorphous aluminum silicate), some aluminum oxide, and small amounts of other oxides. The chemical and physical properties of pumice can strongly influence the durability and strength properties of concrete (Çolak, 2003; Lemougna et al., 2018; Pekmezci \& Akyüz, 2004).

Five treatments were tested (Table 2): reference samples made with 100\% Portland cement; experimental samples made with Portland cement and 10 or $20 \mathrm{wt} \%$ fly ash; and experimental samples made with Portland cement and 10 or $20 \mathrm{wt} . \%$ pumice. Binder dosage and pulp density were maintained at 5 and 80 wt.\%, respectively.

Backfill samples were cured for 7, 14, or 28 days in a moist cabinet, where temperature and relative humidity were maintained at $25 \pm 2{ }^{\circ} \mathrm{C}$ and $90 \pm 2 \%$, respectively, to simulate underground conditions. At each curing age, two samples from each batch were tested for UCS at a loading rate of $1 \mathrm{~mm} / \mathrm{min}$ until failure (Figure 2). Duplicate means are reported in the results.

\section{Results}

The mean UCS of backfill samples increased with curing time (Figure 3a). Samples prepared with $20 \%$ pumice had the lowest UCS at all curing times and reference samples had the highest UCS at 14 days 


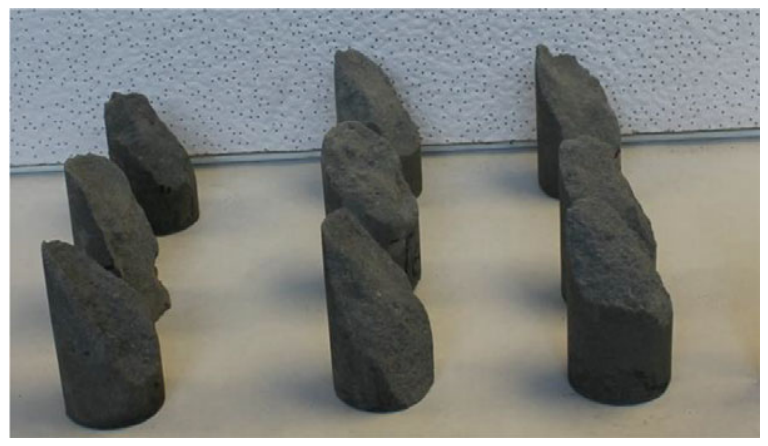

Figure 2. Broken backfill samples after performing uniaxial compressive strength test

a)

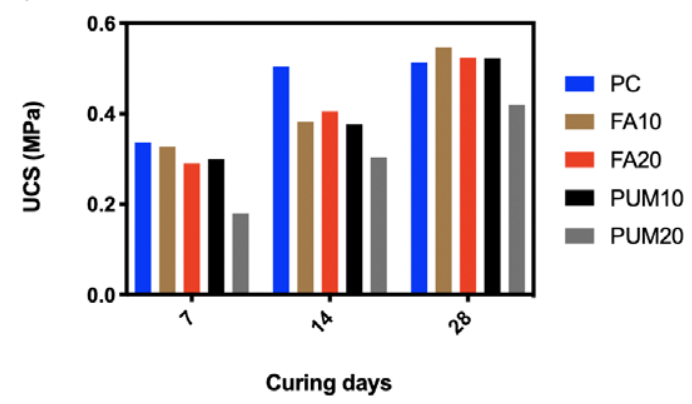

c)

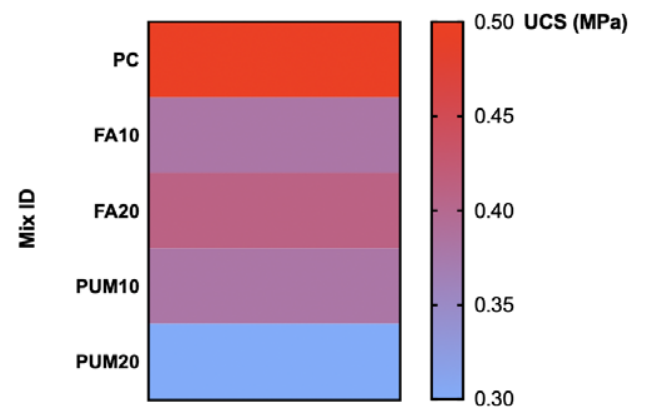

b)

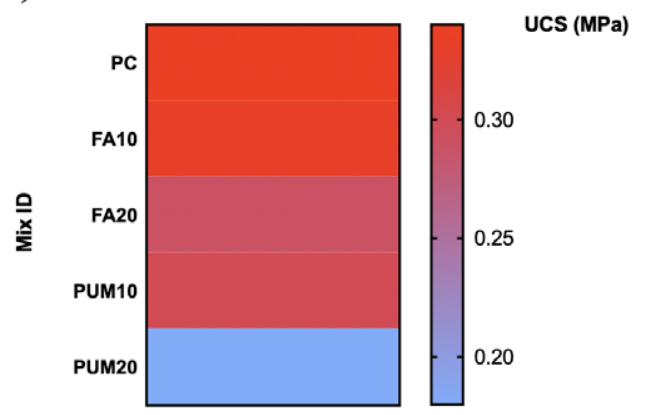

d)

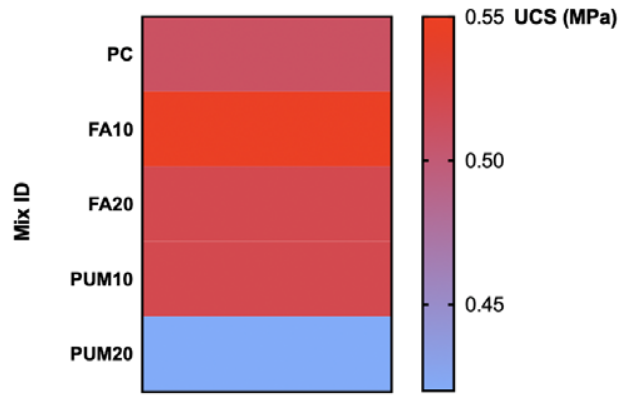

Figure 3. a) Uniaxial compressive strength (UCS) for each cemented mine backfill mixture after 7, 14, and 28 days curing time; heat map for curing times of b) 7 days, c) 14 days, and d) 28 days

curing time (Figure 3a). By 28 days curing time, the reference, fly ash, and $10 \%$ pumice samples had almost similar UCS values (0.51-0.55 MPa), whereas backfill prepared with $20 \%$ pumice was approximately $19 \%$ lower $(0.42 \mathrm{MPa})$.

\section{Discussion}

The results indicate that after 7 and 14 days of curing, poorer strength was achieved for fly ash and pumice samples than reference samples, which is expected since these pozzolans have a slower hydration rate than Portland cement. However, after 28 days of curing, backfill containing 10 or $20 \%$ fly ash or $10 \%$ pumice can achieve almost a similar UCS as backfill prepared with Portland cement. Thus, partially replacing cement with $10 \%$ pumice appears to be a viable option to achieve a similar UCS at a lower cost. These results agree with those of Zeyad et al. (2019), who studied the use of up to 30\% pumice in high-strength concrete and 
found that replacement with $10 \%$ pumice improved the mechanical properties of the concrete. Although samples with $20 \%$ pumice had the lowest UCS values in the present study, Zeyad et al. (2019) found that samples containing $20 \%$ pumice have the highest strength development after 180 days of curing. Therefore, future work will investigate UCS development in cemented mine backfill prepared with $20 \%$ pumice and cured for at least 180 days.

\section{Conclusion}

This investigation showed that there is a strong potential for the mining industry to exploit abundant natural pozzolans like pumice in backfilling operations. Cement can be replaced by $10 \%$ pumice without compromising UCS and potentially reduce the cost of cement in mine backfilling. Although this study investigated strength development over the short term, the literature suggests that at a higher pumice content, the backfill requires a longer curing time to achieve maximum strength. Future studies will evaluate other types of natural pozzolans cured for 180 days to longer than one year to fully understand the pozzolanic effect on strength development. The use of natural pozzolans to minimize cement consumption in mine backfill will help promote a sustainable and eco-friendly approach to mining.

Acknowledgement. The author would like to thank the technical teams from McGill University and King Abdulaziz University.

Funding. No Funding received.

Conflicts of interest declaration. The author declares no conflict of interest.

Data availability. The data are presented in the manuscript.

Supplementary Materials. To view supplementary material for this article, please visit http://dx.doi.org/10.1017/exp.2020.61.

\section{References}

Al-Amoudi, O. S. B., Ahmad, S., Khan, S. M. S., \& Maslehuddin, M. (2019). Durability performance of concrete containing Saudi natural pozzolans as supplementary cementitious material. Advances in Concrete Construction, 8, 119-126. https:// doi.org/10.12989/acc.2019.8.2.119.

Celik, K., Jackson, M. D., Mancio, M., Meral, C., Emwas, A. H., Mehta, P. K., \& Monteiro, P. J. M. (2014). High-volume natural volcanic pozzolan and limestone powder as partial replacements for portland cement in self-compacting and sustainable concrete. Cement and Concrete Composites, 45, 136-147. https://doi.org/10.1016/j.cemconcomp.2013.09.003.

Çolak, A. (2003). Characteristics of pastes from a Portland cement containing different amounts of natural pozzolan. Cement and Concrete Research, 33, 585-593. https://doi.org/10.1016/S0008-8846(02)01027-X.

Edraki, M., Baumgartl, T., Manlapig, E., Bradshaw, D., Franks, D. M., \& Moran, C. J. (2014). Designing mine tailings for better environmental, social and economic outcomes: A review of alternative approaches. Journal of Cleaner Production, 84, 411-420. https://doi.org/10.1016/j.jclepro.2014.04.079.

Kupwade-Patil, K., Al-Aibani, A. F., Abdulsalam, M. F., Mao, C., Bumajdad, A., Palkovic, S. D., \& Büyüköztürk, O. (2016). Microstructure of cement paste with natural pozzolanic volcanic ash and Portland cement at different stages of curing. Construction and Building Materials, 113, 423-441. https://doi.org/10.1016/j.conbuildmat.2016.03.084.

Lemougna, P. N., Wang, K. T., Tang, Q., Nzeukou, A. N., Billong, N., Melo, U. C., \& Cui, X. M. (2018). Review on the use of volcanic ashes for engineering applications. Resources, Conservation and Recycling, 137, 177-190. https://doi.org/10.1016/ j.resconrec.2018.05.031.

Moufti, M. R., Sabtan, A. A., El-Mahdy, O. R., \& Shehata, W. M. (2000). Assessment of the industrial utilization of scoria materials in central Harrat Rahat, Saudi Arabia. Engineering Geology, 57, 155-162. https://doi.org/10.1016/S0013-7952(00) 00024-7.

Pekmezci, B. Y., \& Akyüz, S. (2004). Optimum usage of a natural pozzolan for the maximum compressive strength of concrete. Cement and Concrete Research, 34, 2175-2179. https://doi.org/10.1016/j.cemconres.2004.02.008.

Zeyad, A. M., Tayeh, B. A., \& Yusuf, M. O. (2019). Strength and transport characteristics of volcanic pumice powder based high strength concrete. Construction and Building Materials. https://doi.org/10.1016/j.conbuildmat.2019.05.026.

Cite this article: Hefni MA (2020). The potential use of pumice in mine backfill Experimental Results, 1, e56, 1-7. https://doi. org/10.1017/exp.2020.61 


\title{
Peer Reviews
}

\author{
Reviewing editor: Dr. Daniel Micallef \\ University of Malta, Environmental Design, Tal-Qroqq, Msida, South, Malta, MSD2080
}

This article has been accepted because it is deemed to be scientifically sound, has the correct controls, has appropriate methodology and is statistically valid, and has been sent for additional statistical evaluation and met required revisions.

doi:10.1017/exp.2020.61.pr1

\section{Review 1: The Potential Use of Natural Pozzolans in Mine Backfill}

Reviewer: Dr. Izhar Mithal Jiskani

China University of Mining and Technology, School of Mines, Xuzhou, China, 221116

Date of review: 05 November 2020

(C) The Author(s), 2020. Published by Cambridge University Press This is an Open Access article, distributed under the terms of the Creative Commons Attribution licence (http://creativecommons.org/licenses/by/4.0/), which permits unrestricted re-use, distribution, and reproduction in any medium, provided the original work is properly cited.

Conflict of interest statement. Reviewer declares none.

Comments to the Author: In this article, Pumice has been investigated to know whether it can be used as a mine backfill material. The results show that it can replace cement by $10 \%$. The manuscript can be further improved by revising it based on the following suggestions.

(1) Include "Pumice" in the title.

(2) The cited literature in the "Introduction" section is quite old. It is suggested to include some recent and more relevant literature.

(3) The samples are prepared using tailings from Nickel mine. Please add details to the study area.

(4) The author claims that the use of Pumice is compared to cement and class F fly ash. However, it is not well elaborated and discussed in the "Results and Discussion" section. Present detailed results and provide a thorough discussion of your findings.

(5) The first two sentences in the "Conclusion" section should be rewritten to make them completely convincing.

(6) Figure 2 and Table 2 are not cited in the text.

(7) Please follow the journal guidelines and recheck the entire manuscript for grammar, spelling, and punctuation errors. Be cautious when writing chemical formulas and equations

\section{Score Card}

Presentation 


\section{Context}

2.8

Does the title suitably represent the article? (25\%)

Does the abstract correctly embody the content of the article? (25\%)

Does the introduction give appropriate context? (25\%)

Is the objective of the experiment clearly defined? $(25 \%)$

Analysis

2.8

Does the discussion adequately interpret the results presented? (40\%)

Is the conclusion consistent with the results and discussion? (40\%)

Are the limitations of the experiment as well as the contributions of the experiment clearly outlined? $(20 \%)$ 


\section{Review 2: The Potential Use of Natural Pozzolans in Mine Backfill}

\section{Reviewer: Dr. Hamed Rafezi PhD (iD}

McGill University Faculty of Engineering, Mining and Materials Engineering, 3450 University st., Adams Building, Room 101, Montreal, Canada, H3A 2A7

Date of review: 05 November 2020

(c) The Author(s), 2020. Published by Cambridge University Press This is an Open Access article, distributed under the terms of the Creative Commons Attribution licence (http://creativecommons.org/licenses/by/4.0/), which permits unrestricted re-use, distribution, and reproduction in any medium, provided the original work is properly cited.

Conflict of interest statement. Reviewer declares none

Comments to the Author: The paper addresses an important topic in the mining industry sustainability. The work is well defined and the "results and discussion" section is scientifically in order with correct control. I would suggest the author consider more elaboration on the environmental and economical benefits of the application of pozzolans to emphasize the significance of the work done; A few sentences could be added to the introduction section accordingly. This experimental research well suits the journal and I would recommend proofreading before the final submission to correct a few typos in the context (e.g. table 3).

\section{Score Card}

Presentation

Does the paper cite relevant and related articles appropriately? (30\%)

\section{Context}

Does the abstract correctly embody the content of the article? (25\%)

Does the introduction give appropriate context? (25\%)

Is the objective of the experiment clearly defined? (25\%)

Analysis

Are the limitations of the experiment as well as the contributions of the experiment clearly outlined? $(20 \%)$ 